\title{
An Avirulent Tomato Powdery Mildew Isolate Induces Localized Acquired Resistance to a Virulent Isolate in a Spatiotemporal Manner
}

\author{
Alireza Seifi, ${ }^{1}$ Teruo Nonomura, ${ }^{2}$ Yoshinori Matsuda, ${ }^{2}$ Hideyoshi Toyoda, ${ }^{2}$ and Yuling Bai ${ }^{1}$ \\ ${ }^{1}$ Wageningen UR Plant Breeding, Wageningen University \& Research Center, Droevendaalsesteeg 1, 6708PB Wageningen, \\ The Netherlands; ${ }^{2}$ Laboratory of Phytoprotection Science and Technology, Faculty of Agriculture, Kinki University, Nara 631- \\ 8505, Japan
}

Submitted 21 June 2011. Accepted 28 October 2011.

Hypersensitive response (HR) of plant cells to the attack of pathogens induces resistance to subsequent attacks by a broad spectrum of pathogens, leading to acquired resistance. In this study, we characterized the localized acquired resistance (LAR) in the epidermal cells of tomato. First, we report the discovery of a new isolate of tomato powdery mildew occurring in Japan, KTP-02, which has a different virulence spectrum compared with the previously-characterized isolate, KTP-01. Using these two isolates, we investigated LAR phenomenon in the epidermal cells of tomato plants carrying the $\mathrm{Ol}-4$ resistance gene. $\mathrm{Ol}-4$ encodes a nucleotidebinding site leucine-rich repeat protein that triggers HR in the epidermal cells in response to KTP-01 but not KTP-02. We mounted a single conidium of KTP-01 on a single tomato epidermal cell and then monitored the progress of $H R$ in that cell by live microscopy. Once HR occurred in that cell, we mounted a single conidium of KTP-02 on cells adjacent to or at one-cell distance from the first challenged cells, in different time points. With a digital microscope, we consecutively tracked the progress of HR (i.e., induction of LAR) in those cells. Results showed that, in tomato plants carrying the $\mathrm{Ol}-4$ gene, HR to KTP-01 results in induction of $\mathrm{HR}$ in the adjacent epidermal cells challenged with KTP-02. Our results show that $L A R$ can be triggered only in adjacent cell layer and lasts 24 to $48 \mathrm{~h}$ after HR occurred in the first cell. We did not observe the reverse phenomenon, induced susceptibility to KTP-01 by KTP-02. Altogether, we report an advanced technique for investigating LAR phenomena, and provide data on spatiotemporal characteristics of $L A R$ in tomato epidermal cells.

Acquired resistance in plants has been reported in two forms: localized acquired resistance (LAR) (Ross 1961a; Yarwood 1960) and systemic acquired resistance (SAR) (Ross 1961b). It is known that those pathogens thatcause hypersensitive response (HR) on plant tissues induce resistance to subsequent attacks by a broad spectrum of pathogens in distant tissues, leading to SAR induction (Durrant and Dong 2004), or in cellular layers sur-

A. Seifi and T. Nonomura contributed equally to this work.

Corresponding authors: Y. Bai; E-mail: bai.yuling@wur.nl; and H. Toyoda; E-mail: toyoda@ nara.kindai.ac.jp

* The $e$-Xtra logo stands for "electronic extra" and indicates that a supplementary video, a supplementary figure, and a supplementary table are published online. rounding the HR, resulting in LAR induction (Costet et al. 1999). Recent evidence suggests that HR is not necessary for the induction of acquired resistance but the events leading to HR probably are required (Hammerschmidt 2009).

It is not clear yet whether LAR and SAR are two facets of the same basic mechanism or whether two separate mechanisms are involved in these two phenomena (Ross 1961b; Ryals et al. 1994). Comparison of the gene expression pattern in LAR and SAR tissues showed that the expression of defense response genes, including pathogenesis-related $(P R)$ genes, is much higher in LAR than that in SAR tissues (Cordelier et al. 2003). Also, activity of $O$-methyltransferases, enzymes of the phenylpropanoid pathway thatis one of the important pathways for defense responses (Dixon 2001), increased in LAR but not in SAR (Cordelier et al. 2003). These comparisons suggest that, even if LAR and SAR are based on the same mechanism, the amplitude of the induced resistance is higher in LAR. Contrasted with SAR, systemic induced susceptibility (SIS) has been also reported; virulent strains of the bacterial phytopathogen Pseudomonas syringae induced systemic susceptibility to secondary P. syringae infections in the host plant Arabidopsis thaliana (Cui et al. 2005).

Oidium neolycopersici is a highly polyphagous fungus, causing powdery white spots on the adaxial tomato leaf surface (Jones et al. 2001). Since the first report in 1986 in the Netherlands, the presence of different $O$. neolycopersici races has been reported in different parts of the world (Bai et al. 2005; Ivic et al. 2009; Yolageldi et al. 2008). The O. neolycopersici isolates identified in the Czech Republic and in Japan, O. neolycopersici $\mathrm{Cz}$ and KTP-01, respectively, showed virulence spectra different from other isolates (Bai et al. 2005).

Tomato response to $O$. neolycopersici is conditioned by several resistance genes, including $\mathrm{Ol}-1$ and $\mathrm{Ol}-4$ (Bai et al. 2003). It has been reported that HR is the main resistance mechanism of tomato to O. neolycopersici (Huang et al. 1998). Particularly, two different forms of HR have been observed in tomato response to O. neolycopersici. Single-cell HR (Bai et al. 2005; Huang et al. 1998), also defined as fast HR (Li et al. 2007), happens in the presence of $\mathrm{Ol}-4$. The $\mathrm{Ol}-4$ gene is derived from Solanum peruvianum LA2172 and is homologous to the Mi-1 gene encoding a nucleotide-binding site leucine-rich repeat (NBS-LRR) protein (Seifi et al. 2011). The resistance conferred by $\mathrm{Ol}-4$ is complete and race-specific, because nearisogenic line (NIL)-Ol-4 is immune to all tested O. neolycopersici isolates except $O$. neolycopersici $\mathrm{Cz}$ (Bai et al. 2005). On the other hand, multiple-cell HR (Bai et al. 2005; Huang et al. 1998), also described as slow HR (Li et al. 2007), occurs in 
tomato plants carrying the $O l-1$ gene. The $O l-1$ gene was identified from the wild tomato species $S$. habrochaites G1.1560 (Huang et al. 2000) and mapped on the long arm of chromosome 6 of tomato (Bai et al. 2005). Resistance mediated by $\mathrm{Ol-1}$ is incomplete and race-nonspecific, because NIL-Ol-1 showed variable levels of resistance to all different $O$. neolycopersici isolates thatwere tested (Bai et al. 2005). HR is the hallmark of resistance $(R)$-gene-mediated resistance to biotrophic pathogens (Nimchuk et al. 2003). $O l-1$ is likely not an $R$ gene (Seifi 2011) and the form of cell death in NIL-Ol-1 resembles autophagic programmed cell death (Love et al. 2008).

In this study, we report the discovery of a new $O$. neolycopersici isolate from Japan, KTP-02. We show that KTP-02 resembles the previously reported isolate, KTP-01, for some mycological characteristics but differs from KTP-01 in its virulence spectrum. Subsequently, we describe the LAR phenomenon at the single-cell level in tomato epidermal cells by using the different responses of NIL-Ol-4 to both KTP-01 and KTP-02.

\section{RESULTS}

\section{KTP-02 is a new $O$. neolycopersici isolate}

that suppresses HR associated with the $\mathrm{Ol}-4$ function.

KTP-01 is a Japanese isolate that is virulent on the universally susceptible $S$. lycopersicum 'Moneymaker' (MM) tomato as well as on resistant 'Grace' that was bred in The Netherlands (Kashimoto et al. 2003). In many disease tests with KTP-01 in Japan in 2005 and 2006, NIL-Ol-4 (carrying the Ol-4 gene in MM background) and S. peruvianum LA2172 showed complete resistance to this isolate by triggering $\mathrm{HR}$ in all cells invaded by the fungus (Fig. 1A and C). HR occurred at a single-cell level, preventing any further elongation of the secondary hyphae. In contrast, delayed cell death occurred in both NIL-Ol-1 (carrying the $\mathrm{Ol}-1$ gene in MM background) and S. habrochaites G1.1560 (Fig. 1B and D), leading to incomplete resistance. During the maintenance of $S$. peruvianum LA2172 in Japan in 2009, we discovered the occurrence of an O. neolycopersici isolate capable of infecting this species by producing abundant progeny conidia. We isolated and maintained it via single conidium as a new isolate, KTP-02. To confirm the virulence of KTP-02 to the $\mathrm{Ol}-4$ gene, we compared the response of NIL-Ol-4 with both KTP-01 and KTP-02 isolates (Supplementary Table S1). MM was susceptible to both KTP-01 and KTP-02 isolates. NIL-Ol-4 was completely resistant to KTP-01 by triggering HR. In contrast, NIL-Ol-4 was as susceptible as MM in response to KTP-02 and no HR was observed in cells attacked by KTP-02.

To characterize KTP-02, we compared it with KTP-01 based on the internal transcribed spacer (ITS) sequence of the ribosomal DNA (rDNA) and morphological characteristics. ITS has been used successfully for phylogenetic studies of tomato powdery mildews (Kiss et al. 2001). The ITS sequence analysis revealed that KTP-02 belongs to $O$. neolycopersici species because the ITS sequence was identical to that of KTP-01 and other $O$. neolycopersici isolates (Fig. 2). Morphologically, the size of the conidium, conidiophore, and foot cells and the arrangement of conidia on conidiophores were the same in KTP-01 and KTP-02 (Table 1). Further, we compared the germination rate of conidia of KTP-01 and KTP-02 under different temperature and light-intensity conditions. No difference was found under tested conditions in the germination rate between these two isolates. It is worth mentioning that the optimum temperature for conidial germination was $25^{\circ} \mathrm{C}$. Overall, there is no effect of light intensity on the germination rate in either of these isolates, although KTP-02 conidia germinated faster under low light intensity $(50 \mathrm{~lx})$ at the 2-h time point (Supplementary Fig. S1).
KTP-01 inoculation on single epidermal cells of NIL-Ol-4 induces HR to KTP-02 in the adjacent cells.

Having two $O$. neolycopersici isolates with different virulence spectra, we studied the acquired resistance possibly induced by avirulent strain (KTP-01) against the virulent one (KTP-02) in single-cell level in NIL-Ol-4, by using a digital microscope. In principle, a conidium of KTP-01 was mounted on a single epidermal cell of NIL-Ol-4. This cell underwent $\mathrm{HR}$ at $18 \mathrm{~h}$ after inoculation (Fig. 3). Then a conidium of KTP02 was mounted on a single cell adjacent to the first cell in different time points after occurrence of $\mathrm{HR}$ in the first cell. If there is LAR induced by KTP-01, we expected to observe complete HR to KTP-02 in the adjacent cells. Results showed that in NIL-Ol-4, HR was induced by KTP-02 in cells adjacent to the cell where HR occurred in response to the challenge of KTP-01 (Fig. 4, and the supplementary video).

This induced LAR was observed at $0.5,12$, and $24 \mathrm{~h}$ but not at $48 \mathrm{~h}$ after occurrence of $\mathrm{HR}$ in the first cell $(18 \mathrm{~h}$ after mounting KTP-01 conidium). Also, we tested the possibility of induction of resistance in distal cells. We repeated the previous experiment and, this time, we mounted KTP-02 conidia on one-cell-distant cells in relation to the cell thatwas challenged with KTP-01 conidium. No HR was observed in one-cell-distant cells challenged with KTP-02 (Fig. 3B), suggesting that there is no induced resistance in those cells.

\section{KTP-02 inoculation does not induce susceptibility to KTP-01.}

In order to test the possibility of SIS induction in tomato epidermal cells in response to $O$. neolycopersici, we performed another experiment. We first mounted KTP-02 conidia on a single epidermal cell of NIL-Ol-4. Then, in a time series $(0.5$,
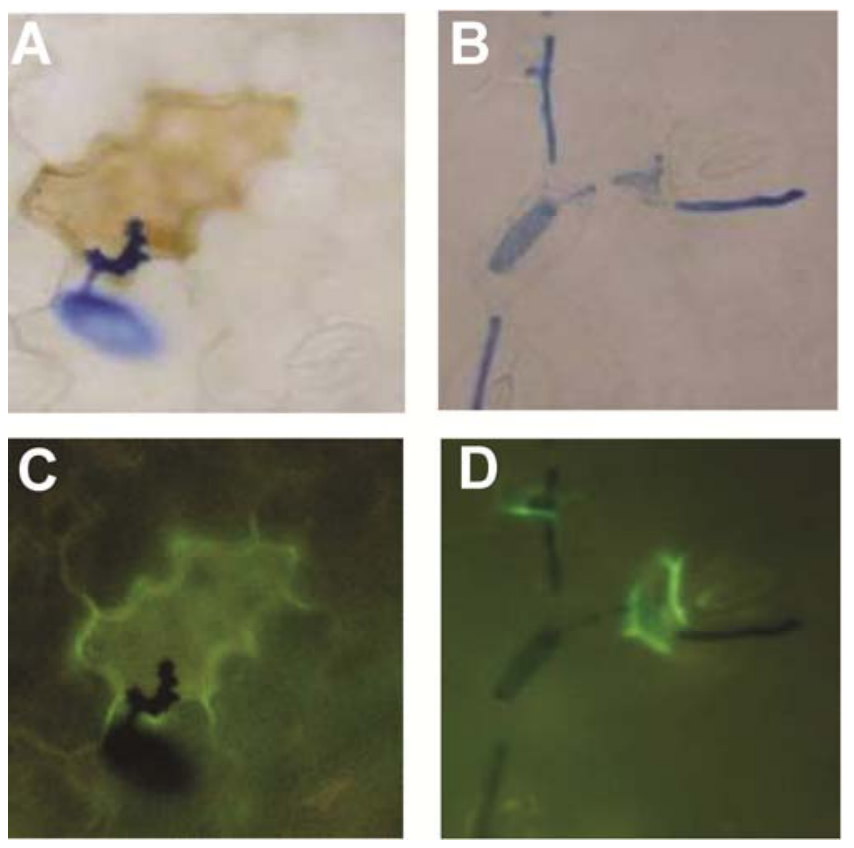

Fig. 1. Death of cells attacked by Oidium neolycopersici KTP-01. A, Tomato epidermal cell, which was attacked by infection pegs of an appressorium of KTP-01 (stained in blue) on a leaf of Solanum peruvianum LA2172, committed hypersensitive response (HR). HR occurred at a single-cell level and prevented any further elongation of the secondary hyphae. B, Tomato epidermal cells of $S$. habrochaites G1.1560 responded to the attack of KTP-01 by triggering delayed cell death (DCD). Compared with HR, DCD developed slowly and allowed the fungus to produce secondary hyphae and the penetration of neighboring cells. $\mathbf{C}$ and $\mathbf{D}$, The same as A and $\mathrm{B}$, respectively, but under the fluorescent microscope. Samples for microscopy were taken 10 days after inoculation. 
12, 24, and $48 \mathrm{~h}$ after appressorial formation of KTP-02), we mounted KTP-01 conidia on cells adjacent to the first challenged cell. If there was an SIS phenomenon induced by KTP02, we expected to observe susceptibility to KTP-01 in the adjacent cells (i.e., no HR). However, in this experiment, all the cells challenged with KTP-01 underwent HR, implying that they were resistant to KTP-01. Therefore, there was no induction of susceptibility to avirulent strain KTP-01 by the virulent one, KTP-02.

\section{DISCUSSION}

Here, we report a new isolate of $O$. neolycopersici, KTP-02, occurring in Japan. The morphological and physiological characteristics of this isolate are similar to those of KTP-01. However, the virulence spectrum of KTP-02 is different from KTP01 because complete resistance mediated by $\mathrm{Ol}-4$ is effective to KTP-01 but not to KTP-02. The O. neolycopersici $\mathrm{Cz}$ isolate also showed a similar virulence spectrum (Bai et al. 2005), which may suggest that KTP-02 and $O$. neolycopersici $\mathrm{Cz}$ belong to the same race. $\mathrm{Ol}-4$, which encodes an NBS-LRR protein, triggers HR in response to KTP-01 but not to KTP-02. In $R$-gene-mediated resistance to biotrophic pathogens, HR occurs as the result of resistance and avirulence recognition (Nimchuk et al. 2003). The fact that no HR occurred in NIL-
Ol-4 cells invaded by KTP-02 suggests that $\mathrm{Ol}-4$ cannot recognize the effectors of KTP-02. It would be interesting to investigate the differences in the effectors of KTP-02 and KTP-01.

In the next step, we investigated the LAR phenomenon in epidermal cells of tomato. We showed that challenging the epidermal cells of NIL-Ol-4 with KTP-01 induces resistance to KTP-02 in one cell layer adjacent to the challenged cell (Fig. 4) and within $48 \mathrm{~h}$ after observing HR in that cell. This fact might imply that some molecules were probably acting as the mobile signals triggering the acquired resistance, similar to signal molecules triggering SAR. It is shown that the signal complex of SAR consists of molecules such as azelaic acid in combination with lipid-derived molecules or lipopeptides (Parker 2009). Symplastic movement of such molecules would be determined by permeability of plasmodesmata of the neighboring cells. Plasmodesmatal permeability could change rapidly; for instance, even slight increases in cytoplasmic calcium concentration cause closure of plasmodesmata in a few seconds (Holdaway-Clarke et al. 2000; Tucker and Boss 1996). It has been reported that wounding results in callose deposition in plasmodesmata, plugging the neck region of plasmodesmata (Hughes and Gunning 1980). Such changes in plasmodesmatal permeability and, therefore, the symplastic movement of signal molecules could be the reason why LAR mediated by challenging the epidermal cells with KTP-01 lasts

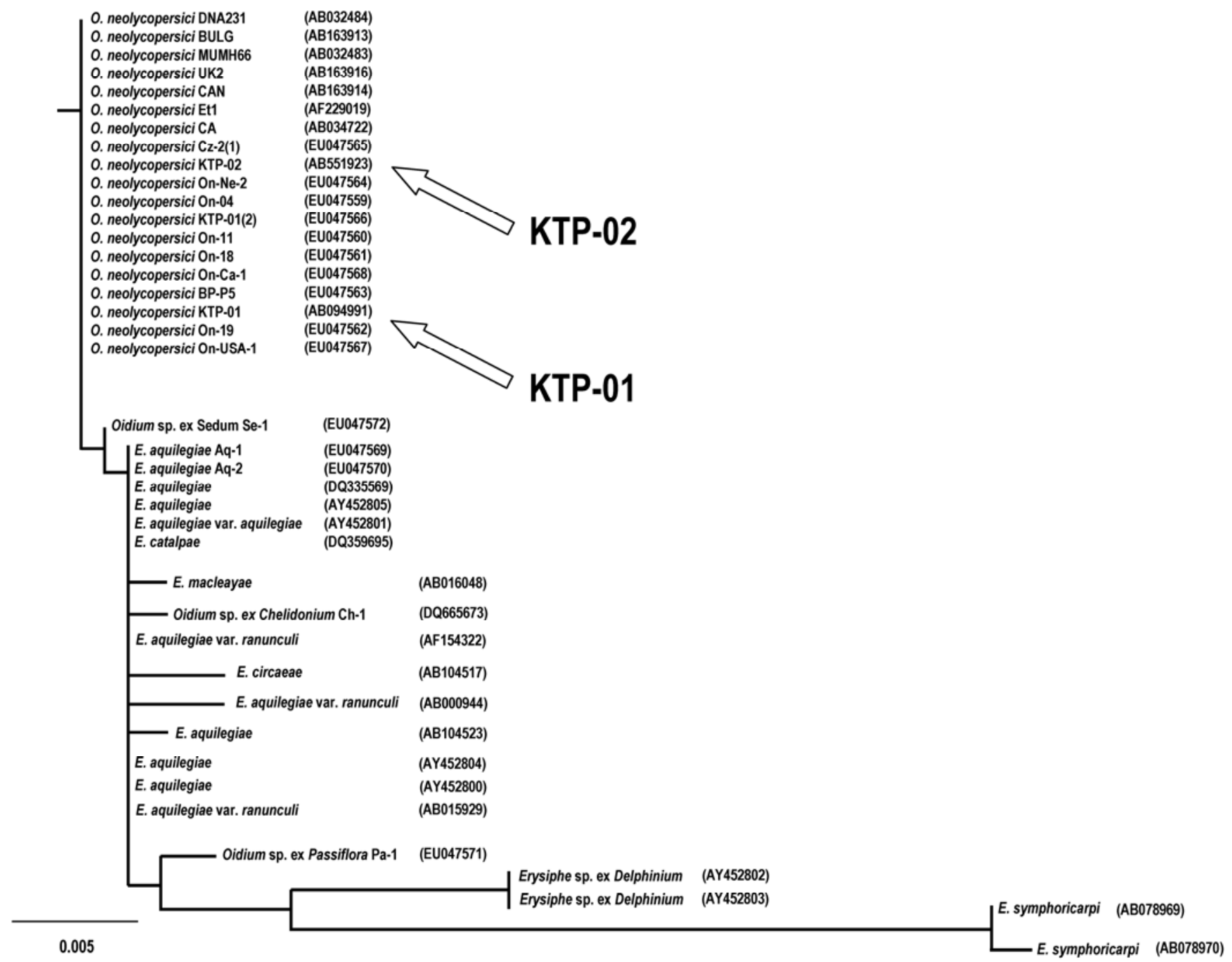

Fig. 2. Phylogenetic tree of different powdery mildew species based on the internal transcribed spacer sequence. The newly discovered powdery mildew isolate, KTP-02, belongs to the Oidium neolycopersici clade. 
between 24 and $48 \mathrm{~h}$ after HR occurrence in the first challenged cell (Fig. 3).

Because there was an example of induced susceptibility in contrast to induced resistance (Cui et al. 2005), we tested the possibility of this phenomenon in our pathosystem. We first challenged a single epidermal cell with KTP-02 and then evaluated the response of adjacent cells to KTP-01. Our results showed that there is no SIS phenomenon in our pathosystem, suggesting that SIS is not a common phenomenon in plantpathogen interactions. SIS reported previously in the $P$. syringae-Arabidopsis pathosystem is probably a consequence of the production of the phytotoxin coronatine, a jasmonic acid mimic, leading to a mutually antagonistic interaction between the salicylic acid and jasmonic acid signaling pathways (Cui et al. 2005).

In summary, we reported here the discovery of a new Japanese isolate of $O$. neolycopersici and described the spatiotemporal kinetic of LAR in tomato epidermal cells. To fully understand the spatiotemporal kinetic of LAR and its limitation on cells adjacent to the infection site, additional molecular analyses of the HR induction by means of appropriated markers are necessary. At this moment, the limiting factor of this molecular analysis is the lack of method to isolate intracellular contents of a single tomato epidermal cell. Currently, we are working on micropipette-manipulation techniques (Fujita et al. 2004) and hope in the near future to monitor the expression of mo- lecular markers for HR in intracellular contents of a single epidermal cell attacked by a fungal appressorium. Further, by performing single-cell transcript and protein profiling, our singlecell studies will help to unravel mobile signals leading to LAR.

\section{MATERIALS AND METHODS}

\section{Plant material.}

NIL harboring the $\mathrm{Ol}-\mathrm{I}$ and $\mathrm{Ol}-4$ genes (Bai et al. 2005) in the genetic background of $S$. lycopersicum MM were used. $S$. habrochaites G1.1560 (donor of $O l-1$ ) and S. peruvianum LA2172 (donor of Ol-4) were also included.

\section{Fungal material.}

Two Japanese isolates (KTP-01 and KTP-02) of $O$. neolycopersici were used in the present study. KTP-01 (Kashimoto et al. 2003) is a laboratory stock and used routinely in Japan to test resistance or susceptibility of tomato plants (Matsuda et al. 2005). KTP-02 was isolated from the diseased leaves of $S$. peruvianum LA2172 (resistant to KTP-01) and identified as $O$. neolycopersici on the basis of its molecular and morphological characteristics in the present study.

KTP-01 and KTP-02 were maintained by inoculating their conidia into cotyledons of 10-day-old seedlings of MM and NIL-Ol-4, respectively. The conidia were collected from co-

Table 1. Comparison of morphological characteristics between KTP-01 and KTP-02

\begin{tabular}{lcc}
\hline Characteristic & KTP-01 & KTP-02 \\
\hline Conidium $(\mu \mathrm{m})$ & $31.8 \pm 2.5 \times 17.7 \pm 1.5$ & $31.2 \pm 4.2 \times 17.1 \pm 1.6$ \\
Conidiophore $(\mu \mathrm{m})$ & $96.9 \pm 13.9$ & $107.2 \pm 12.8$ \\
Foot cell $(\mu \mathrm{m})$ & $37.7 \pm 8.6$ & $40.3 \pm 7.3$ \\
Conidia on conidiophore & Singly, pseudochains of maximum of four conidia & Singly, pseudochains of maximum of four conidia \\
\hline
\end{tabular}
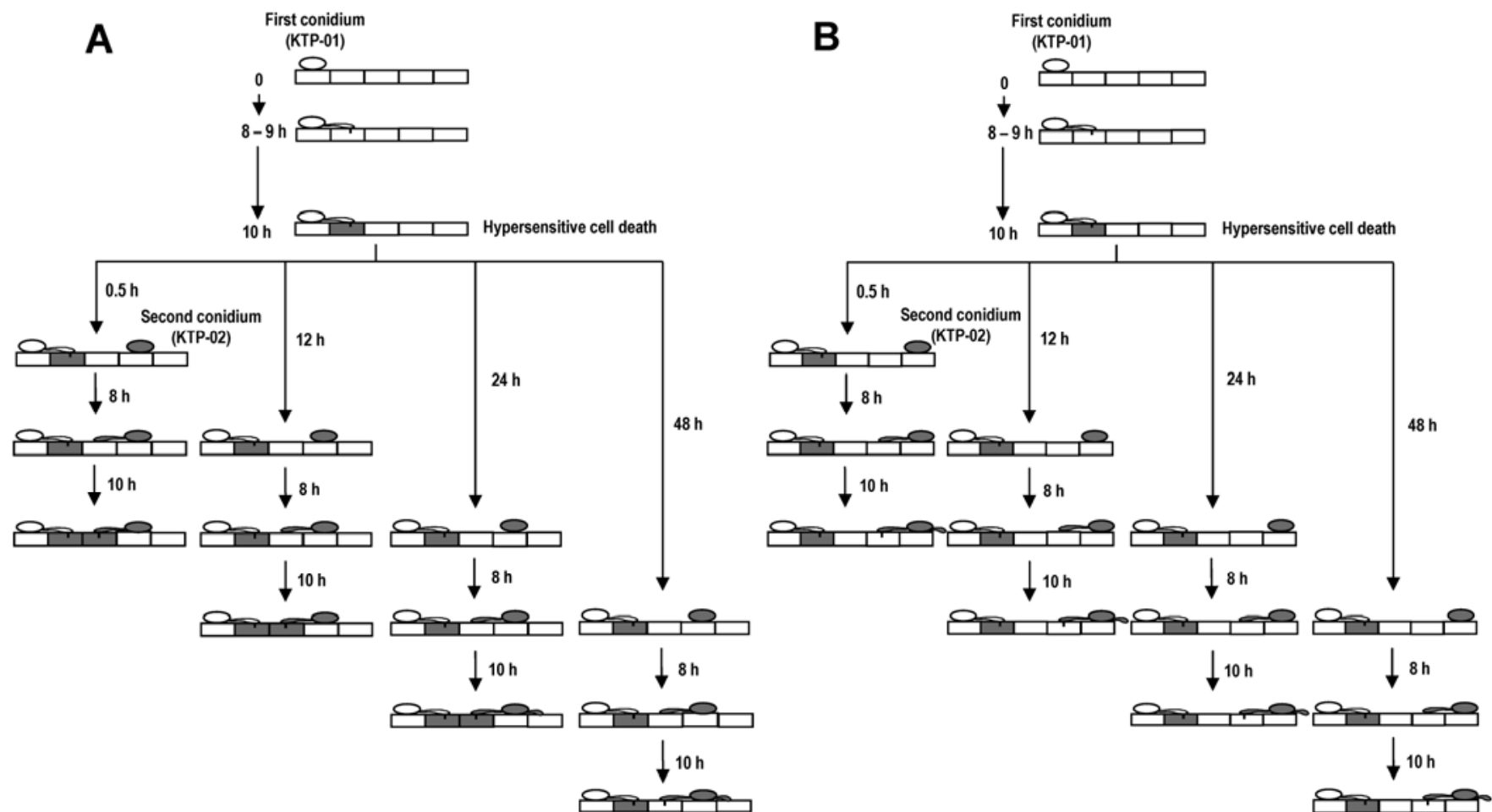

Fig. 3. Localized acquired resistance in epidermal cells of the tomato near-isogenic line Ol-4. Conidium of KTP-01 was mounted on a single epidermal cell. This cell underwent hypersensitive response (HR) (gray colored cells) in response to KTP-01 after $18 \mathrm{~h}$. Upon occurrence of HR in this cell, a conidium of KTP-02 was mounted A, on a single cell adjacent to the first cell or $\mathbf{B}$, in a one-cell-distant cell in a time series of $0.5,12,24$, and $48 \mathrm{~h}$ after occurrence of HR in the first cell. For each time point, 15 conidia were mounted, and then the occurrence of HR in the second cell was monitored. In the adjacent cell (A), the percentage of the cells that showed HR was 74, 67, 40, and 0\% at the 0.5-, 12-, 24-, and 48-h time points, respectively. However, in one-cell-distant cells (B), no occurrence of HR was observed. 
nidiophores on infected leaves and transferred to cotyledons (one conidium per cotyledon) using a glass needle installed with a micromanipulator and a microscope KH-2700 (Nonomura et al. 2009). Inoculated cotyledonal seedlings were placed for 2 weeks in different growth chambers $\left(25 \pm 1^{\circ} \mathrm{C}\right.$ under continuous light of 4,000 lx).

\section{Disease test.}

To prepare abundant conidia used for inoculation, KTP-01 and KTP-02 conidia on the infected cotyledons were collected using an electrostatic spore collection probe (Nonomura et al. 2009), suspended in water, and sprayed onto leaves of MM and NIL-Ol-4, respectively. KTP-01-inoculated MM plants were isolated in a spore-exclusion box $\left(1.5\right.$ by 1 by $\left.2 \mathrm{~m}^{3}\right)$ whose roof and lateral faces were furnished with an electrostatic screen (Matsuda et al. 2006) in a temperature-controlled greenhouse $\left(25 \pm 3^{\circ} \mathrm{C}\right)$ in order to prevent air-carried conidia of KTP-02 from contaminating KTP-01. Successful prevention was confirmed by showing no appearance of KTP-02 colonies on leaves of LA2172 plants that were placed in the box as an indicator. KTP-02-inoculated NIL-Ol-4 plants were placed in a different temperature-controlled greenhouse $\left(25 \pm 3^{\circ} \mathrm{C}\right)$.

Inoculation was conducted according to the method described before (Bai et al. 2005); conidia $\left(2 \times 10^{4}\right.$ conidia $\left./ \mathrm{ml}\right)$ of KTP-01 and KTP-02 were collected from infected leaves of MM and NIL-Ol-4, respectively, and suspended in water to produce inoculum. The inoculum was evenly sprayed on the 4week-old plants. Plants were evaluated for their resistance or susceptibility by disease index (DI). Plants showing no sporulation were scored as resistant $(\mathrm{DI}=0)$. Plants with a high level of sporulation, comparable with that on the susceptible control MM plants, were considered to be susceptible (DI =3).

\section{Sequencing of the rDNA ITS region.}

To determine the rDNA ITS sequence of isolate KTP-02, conidia were collected from inoculated tomato leaves and DNA was extracted using a Qiagen DNeasy plant mini kit (Qiagen, Hilden, Germany). Polymerase chain reaction (PCR) was car-
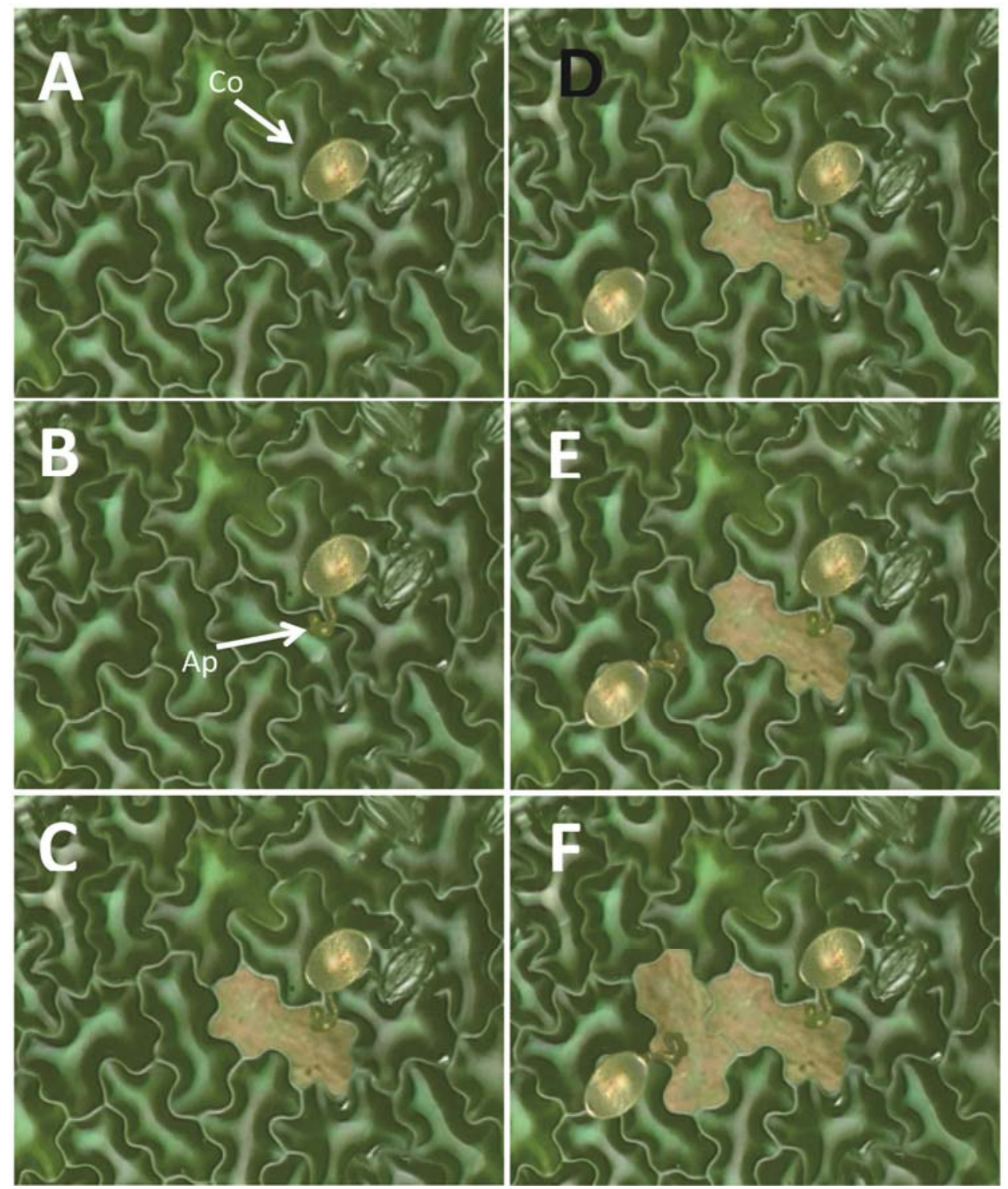

Fig. 4. Consecutive digital micrographs illustrating the induction of localized acquired resistance in tomato epidermal cells. A, A conidium (Co) of Oidium neolycopersici isolate KTP-01 was mounted on a single epidermal cell of near-isogenic line Ol-4 carrying the Ol-4 resistance gene. B, The conidium germinated and produced an appressorium (Ap, approximately 8 to $9 \mathrm{~h}$ after mounting the conidium) for penetration of the epidermal cell. C, Hypersensitive response (HR) occurred in the epidermal cell (starting from approximately $18 \mathrm{~h}$ after mounting the conidium) as the result of the function of the $\mathrm{Ol}-4$ gene. D, Upon occurrence of HR, a conidium of $O$. neolycopersici isolate KTP-02 was mounted on the adjacent epidermal cell. E, The conidium germinated and produced appressorium for penetration. F, HR occurred in the epidermal cell inoculated with KTP-02. 
ried out in an iCycler (Bio-Rad, Hercules, CA, U.S.A.) using the ITS1F and ITS4 fungal-specific primers designed by Gardes and Bruns (1993) and White and associates (1990), respectively. PCR was performed according to the protocols described by Szentiványi and associates (2005). The nucleotide sequence of KTP-02 was deposited at the DNA Data Bank of Japan (DDBJ) under the accession number AB551923.

\section{Phylogenetic analysis.}

The ITS sequences of different powdery mildews were obtained from the DDBJ database, which were combined with KTP-02 in the phylogenetic analysis. The sequences were initially aligned using CLUSTALW. The FIGTREE v1.3.1 software was used to create distance matrices and then to infer dendrograms using neighbor-joining analysis. The strength of groupings was estimated using bootstrap analysis (Felsenstein 1985) with 1,000 replicates.

\section{Single-cell monitoring}

\section{of induced resistance or susceptibility.}

Conidia were collected from conidiophores formed on MM and NIL-Ol-4 cotyledons using a probe of an electrostatic spore collector and were transferred to particular sites of test leaves. In principle, a conidium of KTP-01 was mounted on a single epidermal cell of NIL-Ol-4. This cell underwent HR in response to KTP-01 at $18 \mathrm{~h}$ after inoculation of the KTP-01 conidium. Upon occurrence of HR in this cell, a conidium of KTP-02 was mounted on a single cell adjacent to or with one-cell distance from the first cell in a time series of $0.5,12,24$, and $48 \mathrm{~h}$ after occurrence of HR in the first cell. For each time point, 15 conidia were mounted. By digital microscopic observation, the dead epidermal cells were detectable without any chemical treatments or staining because these cells collapsed and contrasted with the surrounding noncollapsed cells (Nonomura et al. 2010).

\section{Microscopic observation.}

To compare two different forms of cell death, HR and delayed cell death, Japanese isolate KTP-01 (Kashimoto et al. 2003) was applied on S. habrochaites G1.1560 and S. peruvianum LA2172. Inoculation was conducted by collecting conidia on conidiophores with an electrostatic spore collector and suspending them in water containing Mixpower $\left(10^{-5}\right.$ diluted) to produce inoculum (Nonomura et al. 2009). Tested leaves (third and fourth true leaves) of 1-month-old plants were spray inoculated by the method described above. At 2 and 3 days postinoculation, five leaflets of the third and fourth true leaves were harvested from five individual plants per genotype. To observe cytological responses in inoculated tomato leaves, the sample leaves were detached from the plants, decolored in a boiling alcoholic lactophenol solution for 1 to $2 \mathrm{~min}$, and stained with aniline blue, according to a previous method (Sameshima et al. 2004). The leaves were observed under an Olympus light and fluorescence microscope (B excitation, B absorption filter, and O-515 barrier filter). More than $10 \mathrm{co}-$ nidia per leaflet were counted.

\section{LITERATURE CITED}

Bai, Y., van der Hulst, R., Bonnema, G., Marcel, T., Meijer-Dekens, F., Niks, R., and Lindhout, P. 2005. Tomato defense to Oidium neolycopersici: Dominant $\mathrm{Ol}$ genes confer isolate-dependent resistance via a different mechanism than recessive ol-2. Mol. Plant-Microbe Interact. 18:354-362

Bai, Y. L., Huang, C. C., van der Hulst, R., Meijer-Dekens, F., Bonnema, G., and Lindhout, P. 2003. QTLs for tomato powdery mildew resistance (Oidium lycopersici) in Lycopersicon parviflorum G1.1601 co-localize with two qualitative powdery mildew resistance genes. Mol. Plant-Microbe Interact. 16:169-176.
Cordelier, S., de Ruffray, P., Fritig, B., and Kauffmann, S. 2003. Biological and molecular comparison between localized and systemic acquired resistance induced in tobacco by a Phytophthora megasperma glycoprotein elicitin. Plant Mol. Biol. 51:109-118.

Costet, L., Cordelier, S., Dorey, S., Baillieul, F., Fritig, B., and Kauffmann, S. 1999. Relationship between localized acquired resistance (LAR) and the hypersensitive response (HR): HR is necessary for LAR to occur and salicylic acid is not sufficient to trigger LAR. Mol. Plant-Microbe Interact. 12:655-662.

Cui, J., Bahrami, A. K., Pringle, E. G., Hernandez-Guzman, G., Bender, C. L., Pierce, N. E., and Ausubel, F. M. 2005. Pseudomonas syringae manipulates systemic plant defenses against pathogens and herbivores. Proc. Natl. Acad. Sci. U.S.A.102:1791-1796.

Dixon, R. A. 2001. Natural products and plant disease resistance. Nature 411:843-847.

Durrant, W. E., and Dong, X. 2004. Systemic acquired resistance. Annu. Rev. Phytopathol. 42:185-209.

Felsenstein, J. 1985. Confidence limits on phylogenies: An approach using the bootstrap. Evolution 39:783-791.

Fujita, K., Matsuda, Y., Wada, M., Hirai, Y., Mori, K., Moriura, N., Nonomura, T., Kakutani, K., and Toyoda, H. 2004. Powdery mildew pathogens can suppress the chitinase gene expression induced in detached inner epidermis of barley coleoptile. Plant Cell Rep. 23:504-511.

Gardes, M., and Bruns, T. D. 1993. ITS primers with enhanced specificity for basidiomycetes - application to the identification of mycorrhizae and rusts. Mol. Ecol. 2:113-118.

Hammerschmidt, R. 2009. Systemic acquired resistance. Adv. Bot. Res. 51:173-222.

Holdaway-Clarke, T. L., Walker, N. A., Hepler, P. K., and Overall, R. L. 2000. Physiological elevations in cytoplasmic free calcium by cold or ion injection result in transient closure of higher plant plasmodesmata. Planta 210:329-335.

Huang, C. C., Groot, T., Meijer-Dekens, F., Niks, R. E., and Lindhout, P. 1998. The resistance to powdery mildew (Oidium lycopersicum) in Lycopersicon species is mainly associated with hypersensitive response. Eur. J. Plant Pathol. 104:399-407.

Huang, C. C., Hoefs-van de Putte, P. M., Haanstra-van der Meer, J. G. Meijer-Dekens, F., and Lindhout, P. 2000. Characterization and mapping of resistance to Oidium lycopersicum in two Lycopersicon hirsutum accessions: Evidence for close linkage of two $\mathrm{Ol}$-genes on chromosome 6 of tomato. Heredity 85:511-520.

Hughes, J., and Gunning, B. 1980. Glutaraldehyde-induced deposition of callose. Can. J. Bot. 58:250-258.

Ivic, D., Milicevic, T., and Cvjetkovic, B. 2009. First Croatian report of powdery mildew on tomato caused by Oidium neolycopersici. Plant Pathol. 58:802-802

Jones, H., Whipps, J. M., and Gurr, S. J. 2001. The tomato powdery mildew fungus Oidium neolycopersici. Mol. Plant Pathol. 2:303-309.

Kashimoto, K., Sameshima, T., Matsuda, Y., Nonomura, T., Oichi, W. Kakutani, K., Nakata, K., Kusakari, S., and Toyoda, H. 2003. Infectivity of a Japanese isolate of Oidium neolycopersici KTP-01 to a European tomato cultivar resistant to O. lycopersici. J. Gen. Plant Pathol. 69:406408.

Kiss, L., Cook, R. T. A., Saenz, G. S., Cunnington, J. H., Takamatsu, S., Pascoe, I., Bardin, M., Nicot, P. C., Sato, Y., and Rossman, A. Y. 2001. Identification of two powdery mildew fungi, Oidium neolycopersici $\mathrm{sp}$ nov. and $O$. lycopersici, infecting tomato in different parts of the world Mycol. Res. 105:684-697.

Li, C. W., Bonnema, G., Che, D., Dong, L., Lindhout, P., Visser, R., and Bai, Y. L. 2007. Biochemical and molecular mechanisms involved in monogenic resistance responses to tomato powdery mildew. Mol. PlantMicrobe Interact. 20:1161-1172.

Love, A., Milner, J., and Sadanandom, A. 2008. Timing is everything: Regulatory overlap in plant cell death. Trends Plant Sci. 13:589-595.

Matsuda, Y., Mori, Y., Sakano, Y., Nishida, M., Tarumoto, K., Nonomura, T., Nishimura, H., Kusakari, S., and Toyoda, H. 2005. Screening of wild Lycopersicon species for resistance to Japanese isolate of tomato powdery mildew Oidium neolycopersici. Breed. Sci. 55:355-360.

Matsuda, Y., Ikeda, H., Moriura, N., Tanaka, N., Shimizu, K., Oichi, W., Nonomura, T., Kakutani, K., Kusakari, S., Higashi, K., and Toyoda, H. 2006. A new spore precipitator with polarized dielectric insulators for physical control of tomato powdery mildew. Phytopathology 96:967-974.

Nimchuk, Z., Eulgem, T., Holt Iii, B. F., and Dangl, J. L. 2003. Recognition and response in the plant immune system. Annu. Rev. Genet. 37:579-609.

Nonomura, T., Matsuda, Y., Xu, L., Kakutani, K., Takikawa, Y., and Toyoda, H. 2009. Collection of highly germinative pseudochain conidia of Oidium neolycopersici from conidiophores by electrostatic attraction. Mycol. Res. 113:364-372.

Nonomura, T., Nishitomi, A., Matsuda, Y., Soma, C., Xu, L., Kakutani, K. 
Takikawa, Y., and Toyoda, H. 2010. Polymorphic change of appressoria by the tomato powdery mildew Odium neolycopersici on host tomato leaves reflects multiple unsuccessful penetration attempts. Fungal Biol. 114:917-928.

Parker J. E. 2009. The quest for long-distance signals in plant systemic immunity. Sci. Signal. 2:1-3.

Ross, A. F. 1961a. Localized acquired resistance to plant virus infection in hypersensitive hosts. Virology 14:329-339.

Ross, A. F. 1961b. Systemic acquired resistance induced by localized virus infections in plants. Virology 14:340-358.

Ryals, J., Uknes, S., and Ward, E. 1994. Systemic acquired resistance. Plant Physiol. 104:1109-1112.

Sameshima, T., Kashimoto, K., Kida, K., Matsuda, Y., Nonomura, T., Kakutani, K., Nakata, K., Kusakari, S., and Toyoda, H. 2004. Cytological events in tomato leaves inoculated with conidia of Blumeria graminis f. sp. hordei and Oidium neolycopersici KTP-01. J. Gen. Plant Pathol. 70:7-10

Seifi, A. 2011. Characterization of tomato genes for resistance to Oidium neolycopersici. Ph.D. thesis, Wageningen University, Wageningen, Wageningen, The Netherlands.

Seifi, A., Kaloshian, I., Vossen, J., Che, D. D., Bhattarai, K. K., Fan, J. M.,
Naher, Z., Goverse, A., Tjallingii, W. F., Lindhout, P., Visser, R. G. F., and Bai, Y. L. 2011. Linked, if not the same, $M i-1$ homologues confer resistance to tomato powdery mildew and root-knot nematodes. Mol. Plant-Microbe Interact. 24:441-450.

Szentiványi, O., Kiss, L., Russell, J. C., Kovács, G. M., Varga, K., Jankovics, T., Lesemann, S., Xu, X.-M., and Jeffries, P. 2005. Ampelomyces mycoparasites from apple powdery mildew identified as a distinct group based on single-stranded conformation polymorphism analysis of the rDNA ITS region. Mycol. Res. 109:429-438.

Tucker, E. B., and Boss, W. F. 1996. Mastoparan-induced intracellular $\mathrm{Ca}^{2+}$ fluxes may regulate cell-to-cell communication in plants. Plant Physiol. 111:459-467.

White, T. J., Bruns, T., Lee, S., and Taylor, J. 1990. Amplification and direct sequencing of fungal ribosomal RNA genes for phylogenetics. Pages 315-322 in: PCR Protocols: A Guide to Methods and Applications. M. A. Innis, D. H. Gelfand, J. J. Sninsky, and T. J. White, eds. Academic Press, San Diego, CA, U.S.A.

Yarwood, C. E. 1960. Localized acquired resistance to tobacco mosaic virus. Phytopathology 50:741-744.

Yolageldi, L., Sin, B., and Onogur, E. 2008. First report of Oidium neolycopersici on tomatoes in Turkey. Plant Pathol. 57:373-373. 